\title{
Lectin typing of methicillin-resistant Staphylococcus aureus
}

\author{
A. MUÑOZ, O. ALVAREZ, B. ALONSO and J. LLOVO* \\ Department of Microbiology and Parasitology, Faculty of Biology, University of Santiago de Compostela and \\ * Laboratory of Microbiology, Complex Hospitalario Universitario de Santiago (Hospital de Conxo), Spain
}

\begin{abstract}
This study reports the patterns of agglutination of 77 clinical isolates of methicillinresistant Staphylococcus aureus by 32 commercially available lectins. Cell suspensions were not pre-treated. Each isolate was cultured on three media: Columbia blood agar, trypticase-soy agar and Chapman Stone agar. The lectins agglutinating each isolate varied widely depending on culture medium; only five isolates were agglutinated by the same set of lectins regardless of the culture medium used. Lectin typing could be a useful epidemiological tool, but it is necessary to standardise assay conditions (notably culture medium) to enable meaningful comparison of the results produced by different research groups or centres.
\end{abstract}

\section{Introduction}

Staphylococcus aureus, especially methicillin-resistant $S$. aureus (MRSA), is one of the most important causes of nosocomial infection. Furthermore, problems due to MRSA appear to be increasing, particularly in southern Europe, where the incidence of infection and rates of antibiotic resistance are alarmingly high. In Europe, the incidence of methicillin resistance among isolates of $S$. aureus from hospital patients ranges from $<1 \%$ in Scandinavia to $>30 \%$ in France and Italy [1]. In Spain, the incidence of methicillin resistance among hospital isolates of $S$. aureus has increased dramatically over recent years, from $1.5 \%$ in 1986 to $17.9 \%$ in 1996 [2], and to as high as $44 \%$ in some hospitals, giving rise to a serious epidemic situation [3]. The incidence of methicillin resistance among hospital isolates of $S$. aureus also appears to be on the rise in Japan [4].

The selectivity of lectins for microbial surfaces has proved useful in epidemiological studies of disease caused by bacteria of the genera Staphylococcus [5,6], Neisseria [7-9], Haemophilus [10], Campylobacter [11] and Streptococcus [12]. Lectin typing is a simple and economical procedure suitable for use in non-specialist laboratories, either as an adjunct to

Received 1 April 1998; accepted 1 Sept. 1998. Corresponding author: Dr A. Muñoz (e-mail: mpangels@ uscmail.usc.es). serogrouping or, where appropriate, as a sole typing scheme [11].

This study reports the patterns of agglutination of 77 clinical isolates of MRSA by 32 commercially available lectins. The bacterial suspensions were not pretreated, as the aim was to investigate the binding of lectins to bacteria whose surface structure had not been modified. All isolates were tested after culture in Columbia blood agar, trypticase-soy agar and Chapman Stone agar, to investigate whether culture medium affects subsequent lectin binding.

\section{Materials and methods}

\section{Lectins}

The lectins used (Table 1) were selected on the basis of their nominal specificities to cover the widest possible range of sugars. All are commercially available (Sigma). Before use, the lectins were resuspended at $1 \mathrm{mg} / \mathrm{ml}$ in phosphate-buffered saline (PBS), $\mathrm{pH} 7.2-$ 7.4 , and stored at $-20^{\circ} \mathrm{C}$ in $500-\mu 1$ Eppendorf tubes.

\section{Bacteria}

A total of 77 MRSA isolates was provided by the Microbiology Laboratory of the Hospital de Conxo (Complexo Hospitalario Universitario de Santiago de Compostela, Galicia, Northwest Spain) between 1990 and 1996. Isolates were from clinical samples from the intensive care unit $(23 \%)$, internal medicine (20\%), 
Table 1. Panel of lectins

\begin{tabular}{|c|c|c|c|}
\hline Lectin & Abbreviation & Common name & Sugar specificity \\
\hline Anguilla anguilla & $\mathrm{AA}$ & Fresh-water eel & $\alpha$-L-fuc \\
\hline Arachis hypogaea & PN & Peanut & b-D-gal(1-3)-D-galNAc \\
\hline Bauhinia purpurea & $\mathrm{BP}$ & Camel's foot tree & $\mathrm{O}-\beta$-D-gal(1-3)-D-galNAc \\
\hline Canavalia ensiformis & Con $\mathrm{A}$ & Jack bean & $\alpha$-D-man, $\alpha$-D-glc \\
\hline Codium fragile & $\mathrm{CF}$ & Green marine algae & D-galNAc \\
\hline Cytisus scoparius & $\mathrm{CS}$ & Scotch broom & galNAc, gal \\
\hline Datura stramonium & DS & Jimson weed & $(\mathrm{D}-\mathrm{glcNAc})_{2}$ \\
\hline Dolichus biflorus & DB & Horse gram & $\alpha$-D-galNAc \\
\hline Erythrina cristagalli & EC & Coral tree & $\beta$-gal(1-4)glcNAc \\
\hline Euonymus europaeus & $\mathrm{EE}$ & Spindle tree & $\alpha$-gal(1-3)-D-gal \\
\hline Galanthus nivalis & GN & Snowdrop bulb & non-reduc. $\alpha$-man \\
\hline Glycine $\max$ & SB & Soybean & D-galNAc \\
\hline Helix pomatia & HP & Edible snail & D-galNAc \\
\hline Lens culinaris & LC & Lentil & $\alpha$-D-man \\
\hline Limulus polyphemus & LP & Horseshoe crab & NeuNac, D-glcNAc, D-galNAc \\
\hline Lycopersicon esculentum & LE & Tomato & $(\mathrm{D}-\mathrm{glcNAc})_{3}$ \\
\hline Maclura pomifera & MP & Osage orange & $\alpha$-D-gal, $\alpha$-D-galNAc \\
\hline Narcissus pseudonarcissus & NP & Daffodil & $\alpha$-D-man \\
\hline Phaseolus limensis & LB & Lima bean & D-galNAc \\
\hline Phaseolus vulgaris & PHA & Red kidney bean & Oligosaccharide \\
\hline Phytolacca americana & PWM & Pokeweed & $(\mathrm{D}-\mathrm{glcNAc})_{3}$ \\
\hline Pisum sativum & PS & Garden pea & $\alpha-D-\operatorname{man}$ \\
\hline Ptilota plumosa & PP & Red marine algae & $\alpha$-D-gal \\
\hline Sambucus nigra & $\mathrm{SN}$ & Elder & $\alpha-N e u N A c-(2-6) \mathrm{gal} / \mathrm{galNAc}$ \\
\hline Solanum tuberosum & ST & Potato & $(\mathrm{D}-\mathrm{glcNAc})_{3}$ \\
\hline Sophora japonica & SJ & Pagoda tree & $\beta$-galNAc \\
\hline Tetragonolobus purpurea & TP & Asparagus pea & $\alpha$-L-fuc \\
\hline Triticum vulgaris & WGA & Wheat-germ & $(\mathrm{D}-\mathrm{glcNAc})_{2}, \mathrm{NeuNAc}$ \\
\hline Ulex europaeus UEAI & UEA 1 & Gorse, furze & $\alpha$-L-fuc \\
\hline Ulex europaeus UEAII & UEA II & Gorse, furze & $(\mathrm{D}-\mathrm{glcNAc})_{2}$ \\
\hline Vicia faba & VF & Fava bean & D-glc, D-man \\
\hline Vicia sativa & VS & - & D-glc, D-Man \\
\hline
\end{tabular}

surgery $(13 \%)$, dermatology $(11 \%)$ or other services $(15 \%)$.

After incubation for $24 \mathrm{~h}$ at $37^{\circ} \mathrm{C}$ on Columbia blood agar, trypticase-soy agar and Chapman Stone agar, cells were harvested and washed three times by centrifugation in PBS at $1000 \mathrm{rpm}$ for $10 \mathrm{~min}$. Cell suspensions in PBS were adjusted to obtain an $A_{550}$ of 1.25 in a DMS Varian Spectrophotometer.

\section{Antibiotic susceptibility testing}

The isolates were tested for methicillin resistance by agar diffusion tests on Mueller Hinton Agar with 1- $\mu \mathrm{g}$ oxacillin disks (Oxoid). Isolates were also assayed with a commercial oxacillin agar screen (BBL oxacillin screen agar; Becton Dickinson, Cockeysville, MD, USA). In all tests, the inoculum size was equivalent to a $0.5 \mathrm{McFarland}$ standard and incubation was for $24 \mathrm{~h}$ at $35^{\circ} \mathrm{C}$.

\section{Agglutination assay}

Assays were performed in 12-well glass plates $(13 \times 9 \times 0.6 \mathrm{~cm})$, by adding $15 \mu 1$ of lectin to $15 \mu 1$ of bacterial suspension in each well and shaking gently for $30 \mathrm{~s}$. In each series a negative control was run in one well by adding $15 \mu \mathrm{l}$ of PBS instead of lectin to the bacterial suspension. Agglutination was assessed by microscopic examination.

\section{Results}

In the present study, cell suspensions were not pretreated, as the aim was to investigate the binding of lectins to MRSA whose surface structure had not been modified. When trypsin or other proteolytic enzymes partially hydrolyse proteoglycans, some carbohydrate residues may become exposed and thus available for binding; equally, however, other residues may be destroyed or modified. Furthermore, pre-treatment increases the duration of the assay [12].

Of the 77 MRSA isolates tested, $16(20.7 \%)$ were auto-agglutinating and thus could not be lectin-typed and $12(15.5 \%)$ were not agglutinated by any of the lectins tested. The agglutination patterns observed for the remaining 49 isolates are listed for each culture medium in Table 2. Regardless of culture medium, the most frequent pattern was no agglutination by any of the lectins used $(27.8 \%$ of isolates following culture in Columbia blood agar; $37.7 \%$ of isolates following culture in trypticase-soy agar; $42.6 \%$ of isolates following culture in Chapman Stone agar).

Of the bacteria cultured on Columbia blood agar, 21 $(65.6 \%)$ of the 32 lectins tested agglutinated at least one isolate. The lectins agglutinating most isolates (for abbreviations see Table 1) were ConA (36 of 61 isolates, 59.0\%), HP (29 isolates, 47.5\%), PS (15 isolates, $24.5 \%)$ and LC (10 isolates, $16.3 \%)$. A total of 30 agglutination patterns was observed, the most 
Table 2. Agglutination patterns

\begin{tabular}{|c|c|c|c|c|c|}
\hline \multirow[b]{2}{*}{ Date } & \multirow[b]{2}{*}{ Unit } & \multirow{2}{*}{$\begin{array}{c}\text { Isolate } \\
\text { No. }\end{array}$} & \multicolumn{3}{|c|}{ Agglutinating lectins after growth on } \\
\hline & & & Columbia blood agar & Trypticase-soy agar & Chapman Stone agar \\
\hline March 93 & Internal medicine & 1 & $\begin{array}{l}\text { Con A, HP, PS, LC, LP, CF, } \\
\text { AA, LE }\end{array}$ & Con A, HP & Con A, HP, AA, PS \\
\hline Oct. 90 & Surgery & 2 & $\begin{array}{l}\text { Con A, HP, PS, LC, WGA, } \\
\text { CF, DS }\end{array}$ & $\begin{array}{l}\text { Con A, HP, WGA, AA, } \\
\text { CF, VF }\end{array}$ & $\begin{array}{l}\text { Con A, HP, WGA, CF, EC, DS, } \\
\text { VF }\end{array}$ \\
\hline Oct. 96 & Surgery & 3 & $\begin{array}{l}\text { Con A, HP, PS, LC, WGA, } \\
\text { CF }\end{array}$ & $\begin{array}{l}\text { Con A, HP, PS, WGA, AA, } \\
\text { LC }\end{array}$ & Con A, HP, AA, WGA, LC \\
\hline March 93 & ICU & 4 & $\begin{array}{l}\text { Con A, HP, LC, WGA, CF, } \\
\text { AA }\end{array}$ & Con A, HP, WGA, AA, CF & $\begin{array}{l}\text { Con A, HP, AA, WGA, LC, LE, } \\
\text { GN }\end{array}$ \\
\hline Jan. 93 & Dermatology & 5 & Con A, HP, PS, LC, AA & Con A, HP, PS & $\mathrm{HP}$ \\
\hline Oct. 96 & Surgery & 6 & Con A, HP, PS, LC, AA & Con A, HP, PS & HP, PS \\
\hline June 92 & Surgery & 7 & Con A, HP, LP, SN, VF & Con A, HP & Con $\mathrm{A}, \mathrm{HP}, \mathrm{LP}$ \\
\hline Aug. 95 & ICU & 8 & Con A, HP, WGA, CF, PN & Con A, HP, WGA, CF & Con A, HP, AA, WGA, CF, PN \\
\hline July 93 & $\mathrm{ICU}$ & $9^{*}$ & Con A, HP, WGA, AA, EC & Con A, HP, WGA, AA, EC & Con A, HP, AA, WGA, EC \\
\hline Jan. 92 & Internal medicine & 10 & PS, NP, SB, ST, VS & SB & HP, WGA, PHA, SB \\
\hline Jan. 93 & $\mathrm{ICU}$ & 11 & Con A, HP, PS, LC & HP & HP, ST \\
\hline Aug. 96 & Surgery & $12+$ & Con A, HP, PS, LC & Con A, HP & Con $\mathrm{A}, \mathrm{HP}$ \\
\hline Jan. 93 & ICU & 13 & Con A, HP, PS, LP & Con A, HP, PS & Con A, LP, PS \\
\hline July 92 & Dermatology & $14^{*}$ & Con A, HP, LP, EE & Con A, HP, LP, EE & Con A, HP, LP, EE \\
\hline Dec. 95 & Staff & 15 & Con A, HP, LP, NP & Con A, HP, LP & Con A, HP, LP, AA, LC, LE \\
\hline Oct. 93 & Surgery & 16 & Con $\mathrm{A}, \mathrm{HP}, \mathrm{WGA}, \mathrm{EE}$ & Con A, HP, WGA & Con A, WGA \\
\hline Dec. 95 & Staff & 17 & Con A, HP, DS, LE & Con A, HP, LE & Con A, HP, AA, LE, TP \\
\hline Oct. 92 & ICU & $18+$ & Con $\mathrm{A}, \mathrm{HP}, \mathrm{PS}$ & Con A, HP, PS & Con A, HP \\
\hline Jan. 93 & $\mathrm{ICU}$ & 19 & Con A, HP, PS & HP, PS & PS \\
\hline March 93 & $\mathrm{ICU}$ & $20+$ & Con A, HP, PS & ConA, HP, PS & HP, PS \\
\hline March 96 & $\mathrm{ICU}$ & 21 & Con A, HP, LC & LP & PS, MP \\
\hline July 93 & Internal medicine & $22+$ & Con A, HP, EE & Con A, HP, EE & $\mathrm{EE}$ \\
\hline March 93 & Internal medicine & 23 & Con A, LP, SN & No agglutination & LP \\
\hline Nov. 92 & Internal medicine & $24+$ & Con $\mathrm{A}, \mathrm{HP}$ & $\mathrm{HP}$ & HP \\
\hline Nov. 92 & Dermatology & 25 & Con A, HP & No agglutination & No agglutination \\
\hline March 93 & Internal medicine & 26 & Con A, HP & HP & No agglutination \\
\hline March 93 & ICU & 27 & Con A, HP & Con A, HP, WGA & HP, LP, AA \\
\hline March 95 & ICU & $28^{*}$ & Con $\mathrm{A}, \mathrm{HP}$ & Con $\mathrm{A}, \mathrm{HP}$ & Con $\mathrm{A}, \mathrm{HP}$ \\
\hline Aug. 95 & Surgery & 29 & Con A, HP & Con A, HP, LC & Con A, LC \\
\hline Nov. 92 & Dermatology & 30 & Con A, PS & No agglutination & No agglutination \\
\hline Oct. 92 & ICU & $31+$ & Con A, LP & Con A & Con A, LP \\
\hline Oct. 92 & ICU & $32^{*}$ & Con A, LP & Con A, LP & Con A, LP \\
\hline Feb. 93 & Internal medicine & 33 & HP, PS & No agglutination & HP \\
\hline May 92 & Urology & 34 & HP, EE & HP & No agglutination \\
\hline Jan. 95 & ICU & 35 & LC, DB & HP, LC & HP, LC, CF, MP, PP, DB \\
\hline July 93 & ICU & 36 & Con A & Con A, SJ, UEAII & Con $\mathrm{A}, \mathrm{LC}$ \\
\hline Nov. 95 & Internal medicine & $37+$ & Con A & Con A, HP & Con $\mathrm{A}$ \\
\hline April 96 & Internal medicine & 38 & Con A & No agglutination & No agglutination \\
\hline June 96 & ICU & 39 & Con $\mathrm{A}$ & No agglutination & No agglutination \\
\hline June 96 & ICU & 40 & Con $\mathrm{A}$ & No agglutination & No agglutination \\
\hline March 93 & ICU & 41 & PS & No agglutination & No agglutination \\
\hline July 96 & Oncology & $42^{*}$ & LP & LP & LP \\
\hline Nov. 96 & Dermatology & 43 & PN & No agglutination & No agglutination \\
\hline April 92 & Internal medicine & 44 & MP & No agglutination & No agglutination \\
\hline Jan. 92 & Internal medicine & 45 & No agglutination & PS & No agglutination \\
\hline June 96 & Dermatology & 46 & No agglutination & LP & No agglutination \\
\hline Jan. 90 & Surgery & 47 & No agglutination & $\mathrm{EE}$ & No agglutination \\
\hline Aug. 95 & Surgery & 48 & No agglutination & MP & No agglutination \\
\hline Nov. 93 & ICU & 49 & No agglutination & No agglutination & UEAI \\
\hline
\end{tabular}

*Isolates agglutinated by the same set of lectins independently of medium.

+ Isolates agglutinated by the same set of lectins after culture in two of the three media.

frequent being agglutination by both ConA and HP (6 isolates, $9.8 \%$ ).

With bacteria cultured on trypticase-soy agar, 16 $(50 \%)$ of the 32 lectins tested agglutinated at least one isolate. The lectins agglutinating most isolates were HP (28 of 61 isolates, 45.9\%), ConA (25 isolates, $40.9 \%$ ), PS ( 8 isolates, $13.1 \%$ ) and WGA ( 7 isolates, $11.4 \%$ ). A total of 24 agglutination patterns was observed, the most frequent being (i) agglutination by both ConA and HP ( 5 isolates, $8.2 \%$ ) and (ii) agglutination by ConA, HP and PS ( 5 isolates, $8.2 \%$ ).
Of the bacteria cultured on Chapman Stone agar, 23 $(71.8 \%)$ of the 32 lectins tested agglutinated at least one isolate. The lectins agglutinating most isolates were HP (22 of 61 isolates, $45.9 \%)$, ConA (20 isolates, $32.7 \%)$, LP ( 9 isolates, $14.7 \%$ ) and AA (8 isolates, $13.1 \%$ ). A total of 27 agglutination patterns was observed, the most frequent being (i) agglutination by HP alone (3 isolates, $4.9 \%$ ) and (ii) agglutination by HP and ConA (3 isolates, $4.9 \%$ ).

Regardless of culture medium, the lectins that bound most isolates were ConA (specific for $\alpha$-D-mannose and $\alpha$-D-glucose) and HP (specific for N-acetyl-D- 
galactose). For a given isolate/medium/lectin combination, repeated assays gave consistent results (data not shown). Table 2 summarises details of the agglutination patterns observed for each isolate after culture in each of the three media, considering only the 49 isolates that were agglutinated in at least one assay (i.e., after culture in at least one medium, by at least one lectin). Only five isolates (nos. 9, 14, 28, 32 and 42) were agglutinated by the same lectins regardless of culture medium, and seven isolates (nos. 12, 18, 20, 22, 24, 31 and 37) were agglutinated by the same set of lectins after culture on two of the three media.

\section{Discussion}

Typing of MRSA strains is necessary for thorough epidemiological investigations of sources and modes of spread of these strains in hospitals and to design appropriate control measures [13]. Traditional typing methods, such as phage typing and determination of antimicrobial agent resistance profiles, often suffer from insufficient reproducibility, limited discriminatory power, or poor specimen typability, and a number of MRSA strains are not typable with routine phage panels, although use of supplementary phage panels may be helpful [14-19]. The variability inherent in discriminating among strains by phenotypic methods has stimulated interest in DNA-based typing systems [20-23]; but some MRSA strains lack plasmids and are therefore non-typable by plasmid profiling. However, molecular biology methods are costly, time-consuming and technically demanding, and they require interlaboratory standardisation [24]. Currently, there is no single definitive typing system for distinguishing between individual strains of MRSA [25].

The ideal typing system should be rapid, inexpensive, technically simple and readily available. All these conditions are fulfilled by the lectins; moreover they are extremely sensitive to subtle structural differences among bacterial isolates and lectin typing allows differentiation of a greater number of MRSA groups than other typing systems [26].

As shown by the isolation dates (Table 2), strains sharing the same set of lectins were isolated during very short periods (isolates 24 and 25; 31 and 32; 39 and 40), with a high probability of being identical, and were also isolated after long periods of time (isolates 5 and 6;11 and 12;18, 19 and 20;25 and 26; 36, 37 and 38), which may indicate periodic outbreaks of hospital endemic clones. Molecular genetic methods are required to establish the epidemiological origin of these strains; however, the results of the present study indicate that lectin typing may constitute a good first approach to the epidemiology of MRSA, as it can be performed rapidly in the routine of clinical laboratories.
Jarlov et al. (1993) identified a series of 'lectin types' when they examined MRSA isolates from Denmark, the UK and Singapore [26]. However, they did not specify the culture medium used. This is of critical importance in view of the present results, which indicate that the lectins that bind to a given MRSA isolate vary widely depending on the medium on which the isolate was cultured. This variation may be attributable to variation in the composition of different media, which may in turn affect the expression of sugar residues on the bacterial cell surface.

These results strongly suggest a need for researchers to specify the culture medium used in studies of this type, and ideally to agree on a single standard medium to be used for lectin typing of a given bacterium (in this case MRSA). As we have remarked previously [12], practising clinical microbiologists will reap the full benefits of lectin typing only when researchers have agreed on some degree of methodological standardisation. In the absence of larger-scale studies, we tentatively propose Columbia blood agar as the standard medium for lectin typing of MRSA, as it gave the largest number of binding patterns in the present study.

This research was performed under project XUGA 20006B96 (Xunta de Galicia, Spain).

\section{References}

1. Voss A, Milatovic D, Wallrauch-Schwarz C, Rosdahl VT, Braveny I. Methicillin-resistant Staphylococcus aureus in Europe. Eur J Clin Microbiol Infect Dis 1994; 13: 50-55.

2. Cercenado E, Sanchez-Carrillo C, Alcalá L, Bouza E, y Grupo de Trabajo para el Estudio de Estafilococos. Situación actual de la resistancia de Staphylococcus en España. Cuarto Estudio Nacional (1996). Rev Clin Esp 1997; monográfico 2: 18-24.

3. Vindel A, Trincado P, Gomez E et al. An additional set of phages to characterize epidemic methicillin-resistant Staphylococcus aureus strains from Spain (1989/92). Epidemiol Infect 1994; 112: 299-306.

4. Nishijima S, Sugimachi T, Higashida T, Asada Y, Okuda K, Murata K. [An epidemiological study of methicillin-resistant Staphylococcus aureus (MRSA) isolated from medical staffs, inpatients and hospital environments at our hospital.] Nippon Rinsho 1992; 50: 1004-1009.

5. Davidson SK, Keller KF, Doyle RJ. Differentiation of coagulase-positive and coagulase-negative Staphylococci by lectins and plant agglutinins. $J$ Clin Microbiol 1982; 15: $547-553$.

6. Jarløv JO, Hansen J-ES, Rosdahl VT, Espersen F. The typing of Staphylococcus epidermidis by a lectin-binding assay. $J$ Med Microbiol 1992; 37: 195-200.

7. Doyle RJ, Nedjat-Haiem F, Keller KF, Frasch CE. Diagnostic value of interactions between members of the family Neisseriaceae and lectins. J Clin Microbiol 1984; 19: 383-387.

8. Schalla WO, Whittington WL, Rice RJ, Larsen SA. Epidemiological characterization of Neisseria gonorrhoeae by lectins. $J$ Clin Microbiol 1985; 22: 379-382.

9. Vázquez JA, Berrón S. Lectins agglutination test as an epidemiological marker for Neisseria gonorrhoeae. Genitourin Med 1990; 66: 302

10. Korting HC, Abeck D, Johnson AP, Ballard RC, TaylorRobinson D, Braun-Falco O. Lectin typing of Haemophilus ducreyi. Eur J Clin Microbiol Infect Dis 1988; 7: 678-680.

11. O'Sullivan N, Benjamin J, Skirrow MB. Lectin typing of Campylobacter isolates. J Clin Pathol 1990; 43: 957-960.

12. Muñoz A, Lopez A, Llovo J. Lectin typing of beta-haemolytic 
streptococci of groups A and B. J Med Microbiol 1994; 41: 324-328.

13. Deplano A, Vaneechoutte M, Verschraegen G, Struelens MJ. Typing of Staphylococcus aureus and Staphylococcus epidermidis strains by PCR analysis of Inter-IS256 spacer length polymorphisms. J Clin Microbiol 1997; 35: 2580-2587.

14. Archer GL, Mayhall CG. Comparison of epidemiological markers used in the investigation of an outbreak of methicillin resistant Staphylococcus aureus infections. J Clin Microbiol 1983; 18: 395-399.

15. Melo Cristino JA, Torres Pereira A. Plasmid analysis of 219 methicillin-resistant Staphylococcus aureus strains with uncommon profiles isolated in Lisbon. J Hosp Infect 1989; 13: $133-141$.

16. Kerr S, Kerr GE, Mackintosh CA, Marples RR. A survey of methicillin resistant Staphylococcus aureus affecting patients in England and Wales. $J$ Hosp Infect 1990; 16: 35-48.

17. Khalifa KI, Heiba AA, Hancock G. Nontypeable bacteriophage pattern of methicillin-resistant Staphylococcus aureus involved in a hospital outbreak. $J$ Clin Microbiol 1989; 27: 2249-2251.

18. Richardson JF, Chittasobhon N, Marples RR. Supplementary phages set for the investigation of strains of methicillinresistant Staphylococcus aureus. J Med Microbiol 1988; 25: 67-74.

19. Rosdahl VT, Knudsen AM. The decline of methicillin resistance among Danish Staphylococcus aureus strains. Infect Control Hosp Epidemiol 1991; 12: 83-88.

20. Blumberg HM, Rimland D, Kiehlbauch JA, Terry PM, Wachsmuth IK. Epidemiologic typing of Staphylococcus aureus by DNA restriction fragment length polymorphisms of rRNA genes: elucidation of the clonal nature of a group of bacteriophage-nontypeable, ciprofloxacin-resistant, methicillinsusceptible $S$. aureus isolates. J Clin Microbiol 1992; 30: 362-369.

21. Monzo-Moreno C, Aubert S, Morvan S, El Solh N. Usefulness of three probes in typing isolates of methicillin-resistant Staphylococcus aureus (MRSA). J Med Microbiol 1991; 35: 80-88.

22. Struelens MJ, Bax R, Deplano A, Quint WGV, Van Belkum A. Concordant clonal delineation of methicillin-resistant Staphylococcus aureus by macrorestriction analysis and polymerase chain reaction genome fingerprinting. J Clin Microbiol 1993; 31: $1964-1970$.

23. Tenover FC, Arbeit $\mathrm{R}$, Archer $\mathrm{G}$ et al. Comparison of traditional and molecular methods of typing isolates of Staphylococcus aureus. J Clin Microbiol 1994; 32: 407-415.

24. Cookson BD, Aparicio P, Deplano A, Struelens M, Goering R, Marples R. Inter-centre comparison of pulsed-field gel electrophoresis for the typing of methicillin-resistant Staphylococcus aureus. J Med Microbiol 1996; 44: 179-184.

25. Tenover FC, Arbeit RD, Goering RV et al. Interpreting chromosomal DNA restriction patterns produced by pulsedfield gel electrophoresis: criteria for bacterial strain typing. J Clin Microbiol 1995; 33: 2233-2239.

26. Jarløv JO, Rosdahl VT, Yeo M, Marples RR. Lectin typing of methicillin-resistant Staphylococcus aureus from Singapore, England and Wales, and Denmark. J Med Microbiol 1993; 39: 305-309. 